\title{
Management of Varicose Vein by Hirudotherapy
}

\author{
Arsheed Iqbal $^{1 *}$, Haider Ali Quraishi ${ }^{1}$, Huma $^{1}$, Arjumad Shah $^{1}$, Adil Rashid $^{2}$, Raheem $^{3}$ \\ ${ }^{1}$ Regional Research Institute of Unani Medicine, University of Kashmir, Srinagar, Jammu and Kashmir, India \\ ${ }^{2}$ Government Degree College, Ganderbal, Jammu and Kashmir, India \\ ${ }^{3}$ C.C.R.U.M., Ministry of AYUSH, Govt. of India, New Delhi, India
}

*Corresponding Author: drarsheediqbal@gmail.com, Mobile-+919419078302

\section{Available online at: www.isroset.org}

Received: 26/Mar/2019, Accepted: 13/Apr/2019, Online: 30/Apr/2019

\begin{abstract}
Varicose veins are veins that have become enlarged and twisted and are commonly found in legs. The calf muscles of the leg pumps. The venous blood back to the heart against the gravity. When the veins become varicose the valves do not function properly as the blood flows backwards and the veins engorge. The varicose veins are most common in the superficial veins of legs and due to high pressure while standing the veins engorging and ulceration can occur. Only ten percent of the venous blood in the legs is returned back by superficial veins, hence the surgical removal can be opted for superficial varicose veins. Other modalities of treatment included sclerotherapy, elastic stockings, leg elevation, exercise, radiofrequency ablation, endovascular laser treatment etc. In this study Hirudotherapy has been done at Regional Research Institute of Unani Medicine, Srinagar for the treatment of varicose vein and has been observed that leech relieves the symptoms of the varicosity by reducing the engorgements of the superficial leg veins and also improve the venous valvular functioning and thus helps to push the blood normally without regurgitation.
\end{abstract}

Keywords-Hirudotherapy, Leech, Varicosevein, Doppler, Regurgitation.

\section{INTRODUCTION}

The term varicose is derived from Latin word "varix" meaning a dilated vein, and is probably taken from 'varus' meaning 'bent'.[1] The term varicosity is applied for multiple, dilated, torturous and elongated veins which have permanently lost their valvular efficiency such as hemorrhoids, varicocele and esophageal varices.[2] According to Unani system of Medicine (USM), bloodletting is based on concept of Humoral imbalance. Their imbalance causes diseases, whereas restoration or the balance leads to health. According to Unani System of Medicine majority of diseases are caused by endogenous factors by excessive accumulation of morbid humors. [1] Bloodletting in the form of venesection, leech therapy and cupping with scarification is an essential part of USM. It has been utilized for preventive as well as therapeutic measures for thousands of years by ancient Unani physicians. [3]The Hirudotherapy is a pain less procedure of bloodletting and in varicose veins of lower legs (Great saphenous vein) leeching has an outstanding importance as palliative treatment. The great saphenous vein is a large, subcutaneous, superficial vein of the leg. It is the longest vein in the body, running along the length of the lower limb, returning blood from the foot, leg and thigh to the deep femoral vein at the triangle. The great saphenous vein originates from where the dorsal vein of the big toe (the Hallux) merges with the dorsal venous arch of the foot. After passing in front of the medial malleolus (where it often can be visualized and palpated), it runs up the medial side of the leg. At the knee, it runs over the posterior border of the medial epicondyle of the femur bone. Although mortality is minimal, morbidity due to lower limb varicosities causes much misery and enormous loss of man power. There reason to choose treatment for varicose veins is cosmetic in developed countries whereas it is the complications in developing countries like India.[4] Hobbs showed varicose veins in the legs could be due to ovarian vein reflux [5] and Lumley and his team showed recurrent varicose veins could be due to ovarian vein reflux.[6] Whiteley and his team reported that both ovarian and internal iliac vein reflux causes leg varicose veins and that this condition affects $14 \%$ of women with varicose veins or $20 \%$ of women who have had vaginal delivery and have leg varicose veins.[7] There is increasing evidence for the role of incompetent perforator veins (or "perforators") in the formation of varicose veins.[8] and recurrent varicose veins.[9]Varicose veins could also be caused by hyperhomocysteinemia in the body, which can degrade and inhibit the formation of the three main structural components of the artery i.e. collagen, elastin and the proteoglycans[10].Owing to the wide use of Hirudotherapy in plastic surgery it has been 
decided by team of researchers at Regional Research Institute of Unani Medicine (C.C.R.U.M) to use leech therapy for the varicose vein.

\section{DIAGNOSIS}

The diagnosis of varicose vein has been done clinically and following techniques of test has been carried out

\section{Trendelenberg test. \\ II. Perthes test. \\ III. Doppler auscultation}

I. Trendelenberg test: The Trendelenberg test can often be used to distinguish patients with superficial venous reflux from those with incompetent deep venous valves.

A. The leg is elevated until the congested superficial veins have all collapsed. An examining hand or tourniquet is used to occlude a varicose vein just below the sapheno-femoral junction $(5 \mathrm{~cm}$ below and medial to the femoral pulse). The patient stands with the occlusion still in place. [11]

B. If the distal varicosity remains empty or fills very slowly, the principal entry point of high pressure into the superficial system has been identified. Rapid filling despite manual occlusion of the suspected high point of reflux that some other reflux is involved.

II. Perthes test: The Perthes test is a traditional technique intended to distinguish antegrade flow from retrograde flow in superficial varices. To perform the test, a tourniquet is placed over the proximal part of the varicose leg in such a way as to compress superficial varicose veins, but not the deep veins. The patient walks or performs toe-stands to activate the calf muscle pump. The calf muscle pump normally causes varicose veins to be emptied, but if deep system obstruction exists, then the varicose veins paradoxically become more congested.[12]

III. Doppler auscultation: Doppler study shows

A. Spheno femoral junction (SJF) incompetence with reflex on valsulva.

B. Spheno popliteal Junction (SPJ) incompetence in case of small sphenous vein involvement.

\section{AIMS AND OBJECTIVES}

The aim of the study is to analyze the efficacy of the Leech therapy in varicose vein of lower limb.

\section{RELATED WORK}

This is a unique research study done at Regional Research Institute of Unani Medicine, Srinagar, in which the Doppler study was conducted for the differential diagnosis and venous valvular study. No such related work has been done till date.

\section{METHODOLOGY}

Hirudotherapy was done scientifically by taking appropriate hygienic measures and about 10-15 leeches were used locally to suck the blood and transmit the important bioactive enzymes which could help in the treatment of varicose veins of lower legs. Hirudotherapy was done after every ten days for a period of 60 day and the patients was fallowed up for a period of one year.

\section{INCLUSION CRITERIA}

1. Aged between 25 to 65 years

2. Either Sex

3. Patients with unilateral and bilateral varicose veins of lower limbs.

\section{EXCLUSION CRITARIA}

I. Patients with varicose veins as well as peripheral vascular disease (PVD).

II. Patients having thrombophlebitis.

III. Patients already having deep vein thrombosis (DVT).

IV. Patients with bleeding disorder.

V. Lower limb varicose veins with pregnancy or per abdominal masses.

\section{SAMPLE SIZE:}

Twenty patient's with lower limb varicosities.

\section{COLLECTION OF DATA}

All the patients presenting with varicose veins of lower limbs and which met the inclusion criteria were selected and detailed history and clinical findings were recorded. The routine investigations were done along with special investigations if necessary.

\section{TABLE-01-DISTRIBUTION OF PATIENTS ACCORDING TO $A G E$}

\begin{tabular}{|c|c|c|c|}
\hline S. No. & Age Group & Number of Patients & Percentage \\
\hline $\mathbf{1}$ & $25-35$ & 3 & 15 \\
\hline $\mathbf{2}$ & $35-45$ & 7 & 35 \\
\hline $\mathbf{3}$ & $45-55$ & 9 & 45 \\
\hline $\mathbf{4}$ & $55-65$ & 1 & 05 \\
\hline & Total & $\mathbf{2 0}$ & \\
\hline
\end{tabular}

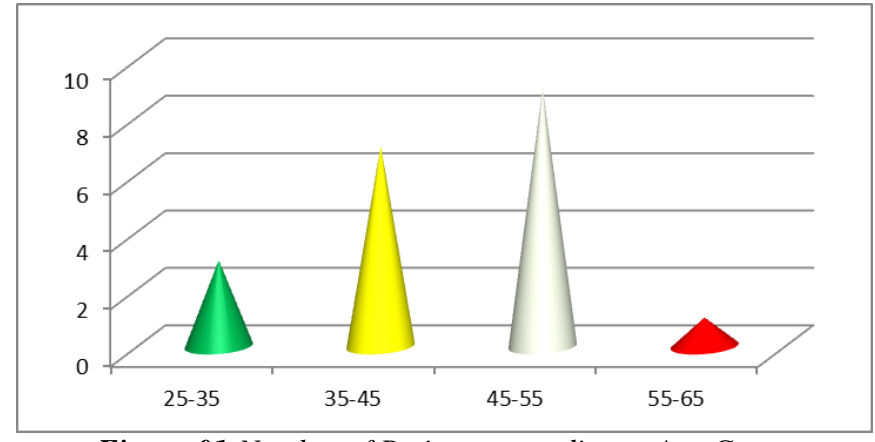

Figure-01-Number of Patients according to Age Group 


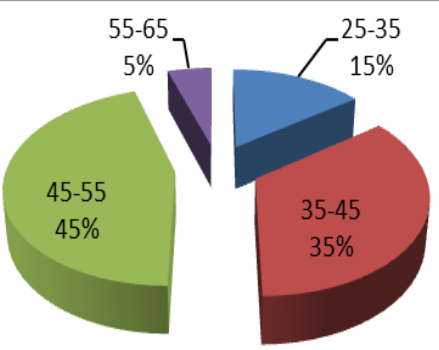

Figure-02- Percentage of Patients according to Age Group

TABLE-02- DISTRIBUTION OF PATIENTS ACCORDING TO GENDER

\begin{tabular}{|c|c|c|c|}
\hline $\begin{array}{c}\text { S. } \\
\text { No. }\end{array}$ & Gender & $\begin{array}{c}\text { Number of } \\
\text { Patients }\end{array}$ & Percentage \\
\hline $\mathbf{1}$ & Male & 17 & 85 \\
\hline $\mathbf{2}$ & Female & 03 & 15 \\
\hline $\mathbf{3}$ & Transgender & 00 & 00 \\
\hline & Total & $\mathbf{2 0}$ & \\
\hline
\end{tabular}

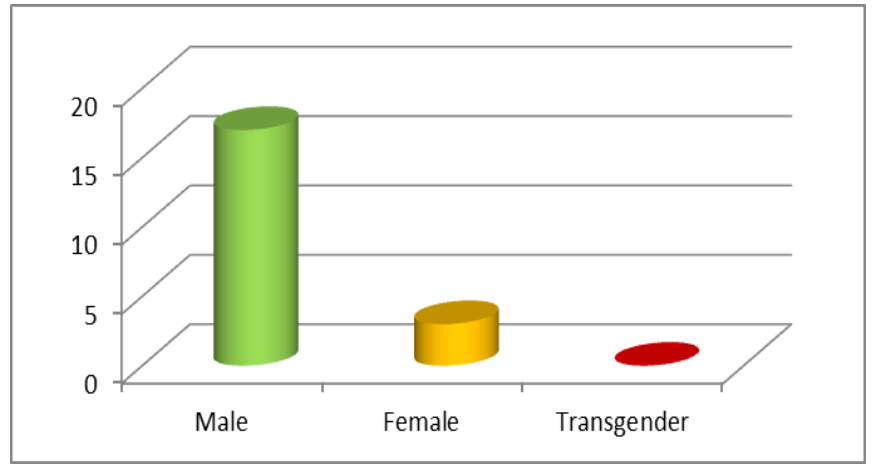

Figur-03-Number of Patients according to Gender

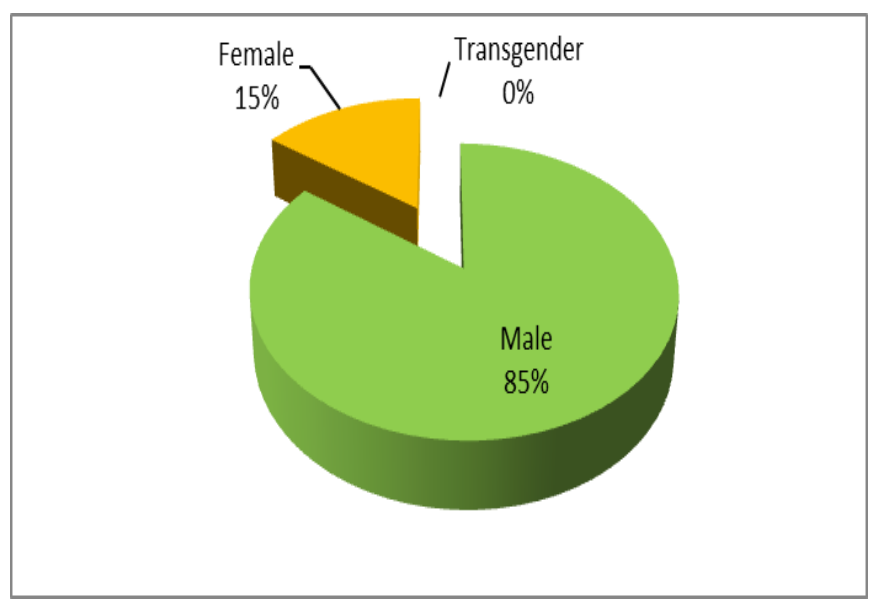

Figure-04-Percentage of Patients according to Gender
Table-03- DISTRIBUTION OF PATIENTS ACCORDING TO MIZAJ (TEMPERAMENT)

\begin{tabular}{|c|c|c|c|}
\hline S. No. & Mizaj (Temperament) & Number of Patients & Percentage \\
\hline $\mathbf{1}$ & Damawi & 08 & 40 \\
\hline $\mathbf{2}$ & Safrawi & 04 & 20 \\
\hline $\mathbf{3}$ & Balghami & 06 & 30 \\
\hline $\mathbf{4}$ & Saudawi & 02 & 10 \\
\hline & Total & $\mathbf{2 0}$ & \\
\hline
\end{tabular}

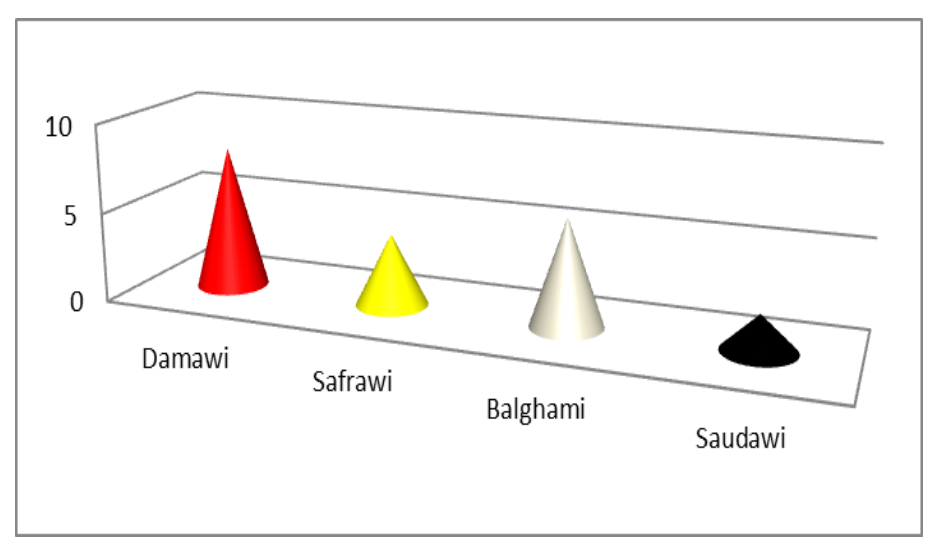

Figure-05-Number of Patients according to Mizaj

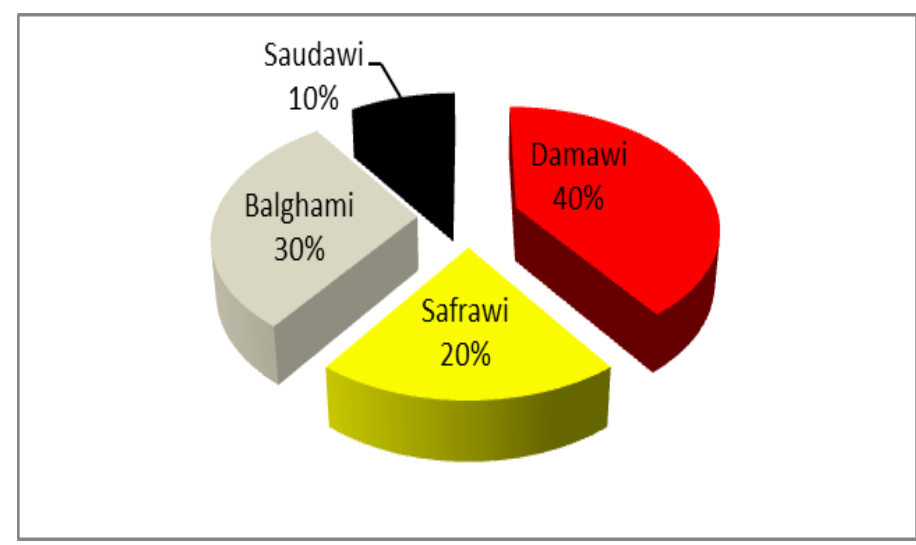

Figure-06-Percentage of Patients according to Mizaj

Table-04-DISTRIBUTION OF PATIENTS ACCORDING TO OCCUPATION

\begin{tabular}{|c|c|c|c|}
\hline $\begin{array}{c}\text { S. } \\
\text { No. }\end{array}$ & Occupation & Number of Patients & Percentage \\
\hline 1 & Agriculture Workers & 11 & 55 \\
\hline 2 & Traffic Police & 01 & 05 \\
\hline 3 & Vendors & 08 & 40 \\
\hline & Total & $\mathbf{2 0}$ & \\
\hline
\end{tabular}




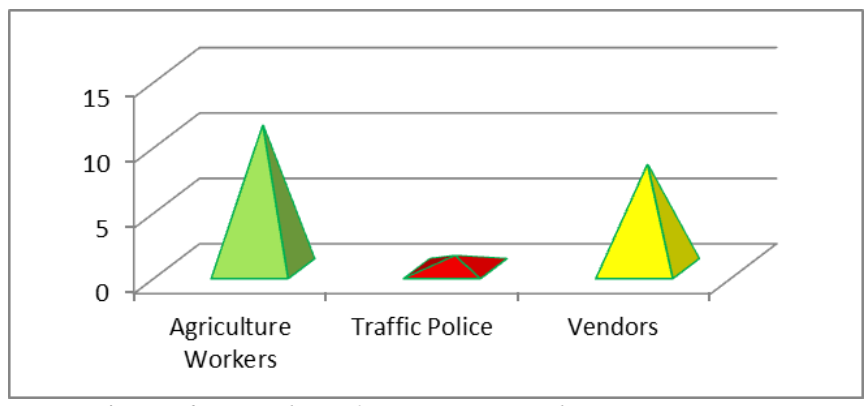

Figure-07-Number of Patients according to Occupation

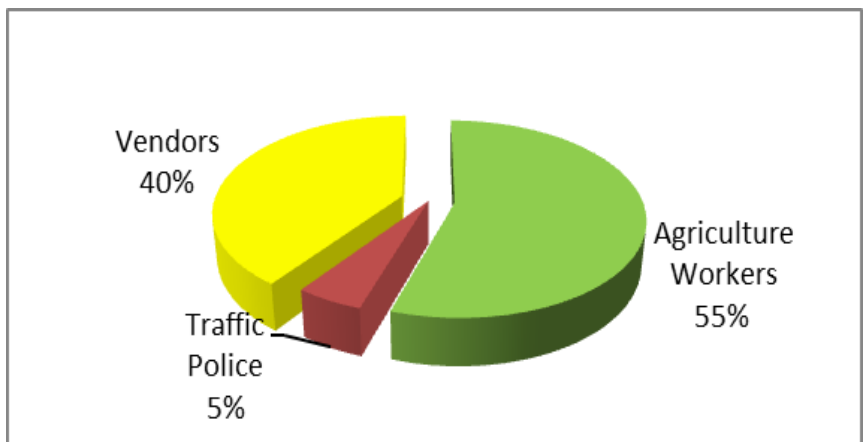

Figure-08-Percentage of Patients according to Occupation

Table-05-DISTRIBUTION OF PATIENTS ACCORDING TO VAS SCORE

\begin{tabular}{|c|c|c|c|}
\hline S. No. & VAS Score & Number of Patients & Percentage \\
\hline $\mathbf{1}$ & Between 1-2 & 14 & 70 \\
\hline $\mathbf{2}$ & Between 2-3 & 04 & 20 \\
\hline $\mathbf{3}$ & Between 3-4 & 02 & 10 \\
\hline & Total & $\mathbf{2 0}$ & \\
\hline
\end{tabular}

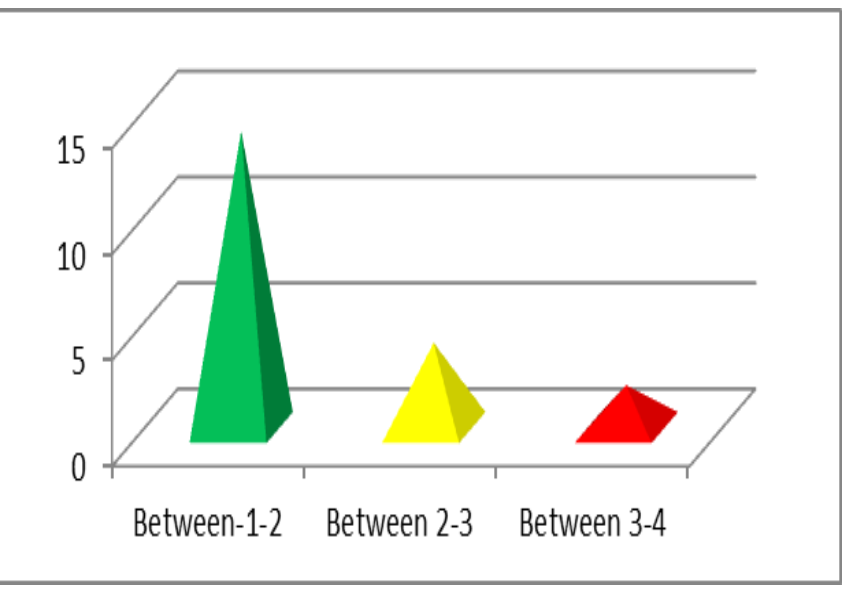

Figure-09-Number of Patients according to VAS Score

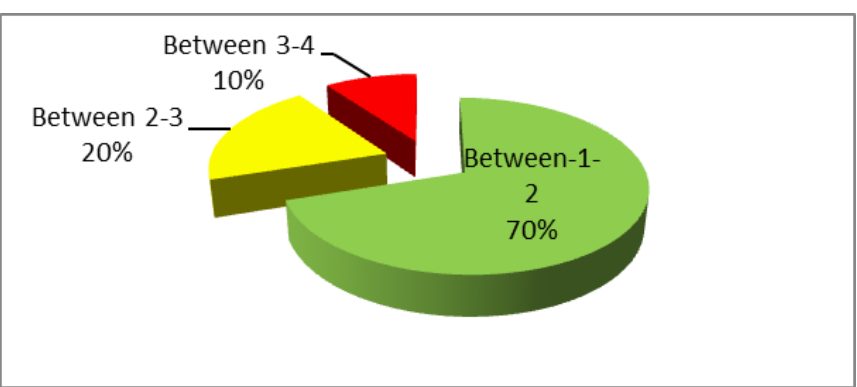

Figure-10-Percentage of Patients according to VAS Score

Table-06- DISTRIBUTION OF PATIENTS ACCORDING TO SOCIO-ECONOMIC STATUS

\begin{tabular}{|c|c|c|c|}
\hline S. No. & VAS Score & Number of Patients & Percentage \\
\hline $\mathbf{1}$ & Lower Class & 08 & 40 \\
\hline $\mathbf{2}$ & Middle Class & 07 & 35 \\
\hline $\mathbf{3}$ & Upper Class & 05 & 25 \\
\hline & Total & $\mathbf{2 0}$ & \\
\hline
\end{tabular}

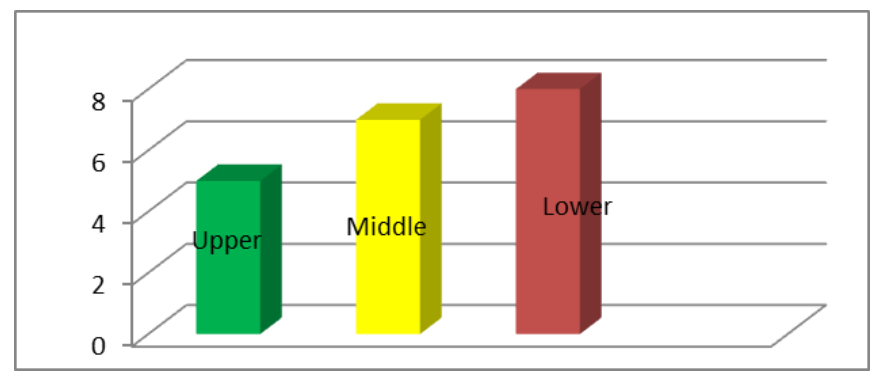

Figure-11- Number of Patients according to Socio economic status

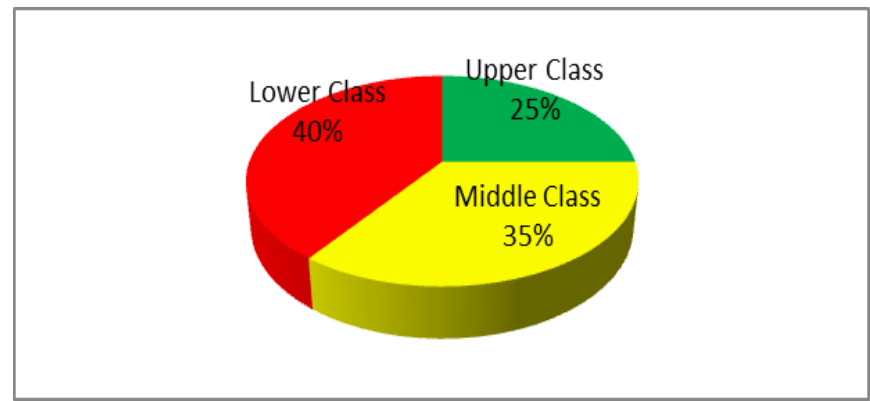

Figure-12- Percentage of Patients according to Socio economic Status

Table-07-DISTRIBUTION OF PATIENTS ACCORDING TO HISTORY

\begin{tabular}{|c|c|c|c|}
\hline S. No. & History & Number of Patients & Percentage \\
\hline $\mathbf{1}$ & Family & 04 & 20 \\
\hline $\mathbf{2}$ & Up to 3 year & 04 & 20 \\
\hline $\mathbf{3}$ & Up to 8 year & 05 & 25 \\
\hline $\mathbf{4}$ & More than 8 year & 07 & 35 \\
\hline & Total & $\mathbf{2 0}$ & \\
& & & \\
\hline
\end{tabular}




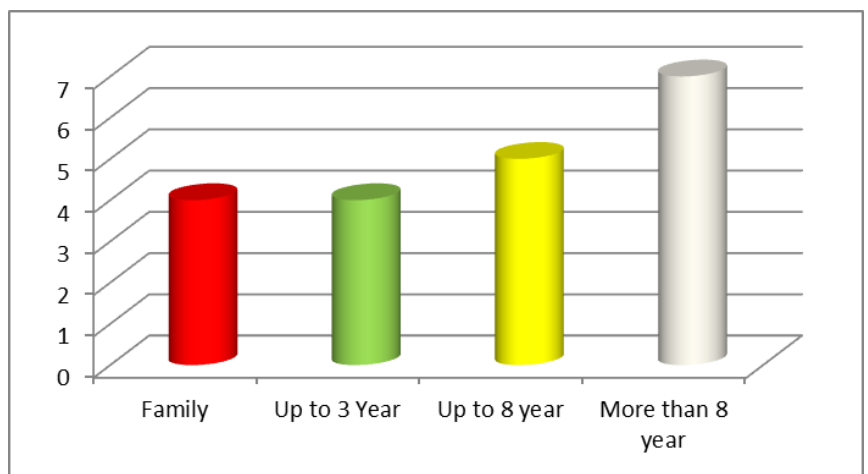

Figure-13- Number of Patients according to History

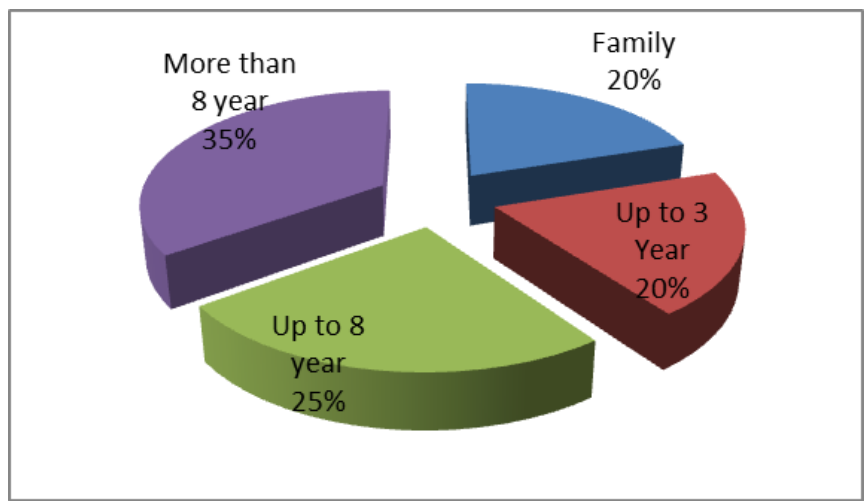

Figure-14- Percentage of Patients according to History

\section{CONSERVATIVE MANAGEMENT}

a) Elevating the legs often provides temporary symptomatic relief.

b) Advice about regular exercise sounds sensible but is not supported by any evidence. [13]

c) The wearing of graduated compression stockings with variable pressure gradients (Class II or III) has been shown to correct the swelling, and improve the microcirculation in legs of affected varicose veins.

d) The wearing of intermittent pneumatic compression devices have been shown to reduce swelling and increase circulation.

e) Anti-inflammatory medication such as ibuprofen or aspirin can be used as part of treatment for superficial thrombophlebitis along with graduated compression hosiery but there is a risk of intestinal bleeding. In extensive superficial thrombophlebitis, consideration should be given to anti-coagulation, thrombectomy or sclerotherapy of the involved vein.

f) Topical gel application helps in managing symptoms related to varicose veins such as inflammation, pain, swelling, itching, and dryness.

\section{STATISTICAL ANALYSIS}

Limb girth at the site of Varicosity in Lower Limb is as fallow.

\begin{tabular}{|c|c|c|}
\hline S. No. & Before Hirudotherapy & After Hirudotherapy \\
\hline $\mathbf{1}$ & $38.1 \mathrm{~cm}$ & $37.1 \mathrm{~cm}$ \\
\hline $\mathbf{2}$ & $36.5 \mathrm{~cm}$ & $35.9 \mathrm{~cm}$ \\
\hline $\mathbf{3}$ & $39.2 \mathrm{~cm}$ & $38.0 \mathrm{~cm}$ \\
\hline $\mathbf{4}$ & $40.3 \mathrm{~cm}$ & $38.8 \mathrm{~cm}$ \\
\hline $\mathbf{5}$ & $43.1 \mathrm{~cm}$ & $42.1 \mathrm{~cm}$ \\
\hline $\mathbf{6}$ & $37.6 \mathrm{~cm}$ & $36.5 \mathrm{~cm}$ \\
\hline $\mathbf{7}$ & $40.9 \mathrm{~cm}$ & $39.1 \mathrm{~cm}$ \\
\hline $\mathbf{8}$ & $39.9 \mathrm{~cm}$ & $38.1 \mathrm{~cm}$ \\
\hline $\mathbf{9}$ & $38.6 \mathrm{~cm}$ & $37.1 \mathrm{~cm}$ \\
\hline $\mathbf{1 0}$ & $39.4 \mathrm{~cm}$ & $37.8 \mathrm{~cm}$ \\
\hline $\mathbf{1 1}$ & $37.8 \mathrm{~cm}$ & $36.9 \mathrm{~cm}$ \\
\hline $\mathbf{1 2}$ & $36.8 \mathrm{~cm}$ & $35.1 \mathrm{~cm}$ \\
\hline $\mathbf{1 3}$ & $37.9 \mathrm{~cm}$ & $36.4 \mathrm{~cm}$ \\
\hline $\mathbf{1 4}$ & $36.9 \mathrm{~cm}$ & $35.0 \mathrm{~cm}$ \\
\hline $\mathbf{1 5}$ & $39.2 \mathrm{~cm}$ & $38.1 \mathrm{~cm}$ \\
\hline $\mathbf{1 6}$ & $39.9 \mathrm{~cm}$ & $38.1 \mathrm{~cm}$ \\
\hline $\mathbf{1 7}$ & $39.1 \mathrm{~cm}$ & $37.9 \mathrm{~cm}$ \\
\hline $\mathbf{1 8}$ & $39.7 \mathrm{~cm}$ & $38.1 \mathrm{~cm}$ \\
\hline $\mathbf{1 9}$ & $38.7 \mathrm{~cm}$ & $36.9 \mathrm{~cm}$ \\
\hline $\mathbf{2 0}$ & $38.9 \mathrm{~cm}$ & \\
\hline & & $37.8 \mathrm{~cm}$ \\
\hline
\end{tabular}

$P$ value

$<0.0001$

$P$ value summary

$* * *$

Are means signif. different? $(\mathrm{P}<0.05) \quad$ Yes

One- or two-tailed $\mathrm{P}$ value?

Two-tailed

$\mathrm{t}, \mathrm{df}$

$t=16.60 \mathrm{df}=19$

Number of pairs

20

Mean of differences

1.385

95\% confidence interval

1.210 to 1.560

$\mathrm{R}$ squared

0.9355

Correlation coefficient (r)

0.9709

P Value (one tailed)

$<0.0001$

$P$ value summary

$* * *$

Was the pairing significantly effective? Yes 
From the above statistical analysis we find that there is significant difference in Limb girth at site of Varicosity in Lower Limb before and after Hirudotherapy.

\section{RESULTS AND DISCUSSION}

\section{Result}

Statistically we find that there is significant difference in Limb girth at site of Varicosity in Lower Limb before and after Hirudotherapy. Clinically there is obvious reduction in the volume of the vessels. The tortuosity of the veins is either vanished or at times reduced. The symptoms like pain, heaviness, itching and change in color re markedly reduced.

\section{Discussion}

Varicose veins can cause a variety of symptoms of discomfort in the legs, but it is important to differentiate these from the many other reasons for leg pains. The Edinburgh vein study found that the symptoms significantly associated with varicose vein were itching, heaviness, and aching, but the relation of these with varicose veins was inconsistent, particularly in men. Superficial thrombophlebitis can complicate varicose veins. The risk of deep vein thrombosis is remote, but in a case series it occurred very occasionally if phlebitis extended above the knee.

Bleeding, skin changes, and ulcers are the complications of varicose veins that mandate consideration of treatment. They are all associated with high venous pressure in the upright position, as a result of incompetent venous valves. Bleeding is uncommon and usually occurs from a prominent vein on the leg or foot with thin, dark, unhealthy skin overlying it. "Skin changes" range from eczema, through brown discoloration, to florid lipodermatosclerosis with indurations of the subcutaneous tissues. Many people have telangiectases on their legs often called thread, spider, or broken veins. Small dark blue reticular veins are also common. Varicose veins pose no proved risk of deep vein thrombosis during people's normal daily lives. Varicose veins occurring as a result of a deep vein thrombosis are uncommon. However, varicose veins may coexist with deep vein incompetence, particularly in people with complications such as lipodermatosclerosis or ulcers, which makes treatment more difficult.

\section{CONCLUSION AND FUTURE SCOPE}

Hirudotherapy in varicose vein has significant positive effect. Prominent improvement has been recorded in symptoms due to potent anti-inflammatory, blood thinning and lymph flow accelerating effect of leech therapy. Presence of natural steroid, Astringents, resolving agents and anticoagulants in leech saliva attributes to the treatment of varicose vein. From above results we conclude that Hirudotherapy was free of side effects and proved great support in managing the symptoms like change in color, engorgement of veins, edema, itching, heaviness and pain in the limb. The Hirudotherapy were also believed to improve the venous valvular functioning by improving spheno femoral junction (SFJ) incompetence and spheno popliteal junction (SPJ) incompetence in case of small sphenous vein involvement. It is also believed that Hirudotherapy maintains the physiological humoral balance of the body and thus helps in combating the varicosity. This study enlightens the researchers to go ahead with multicentric study on large sample size for more information about the efficacy and adverse effects if any.

\section{ACKNOWLEDGMENT}

Authors duly acknowledge the Assistant Director Incharge and OPD and IPD staff, library staff of Regional Research Institute of Unani Medicine, Srinagar, J\&K, India.

\section{CONFLICT OF INTEREST}

There is no any conflict of interest exist.

\section{REFERENCES}

[1]. Tibbs DJ. Varicose veins and related disorders. ButterworthHeinemann; 1992.First edition 25-26.

[2]. Pavan Prasad BK, Prem Kumar A. Clinical Study of varicose veins and their management. International Journal Biomed Advance Res. 2015; 6(08):564-8

[3]. Itrat M, Zarnigar, Haque N. Historical Aspect of Leech Therapy: A Critical Review. International Journal of Health Science and Research. 2013; 3(7):78-83.

[4]. Ng M, Andrew T, Spector T, Jeffery S (2005). "Linkage to the FOXC2 region of chromosome 16 for varicose veins in otherwise healthy, unselected sibling pairs". Journal of Medical Genetics. 42 (3): 235 9. doi:10.1136/jmg.2004.024075. PMC 1736007. PMID 15744037

[5]. Hobbs JT (October 2005). "Varicose veins arising from the pelvis due to ovarian vein incompetence". Int J Clin Pract. Int J Clin Pract. 59: 5031.2005.00631.x. PMID 16178988.

[6]. Giannoukas AD, Dacie JE, Lumley JS (July 2000). "Recurrent varicose veins of both lower limbs due to bilateral ovarian vein incompetence". Ann Vasc Surg. 14: 397400. doi:10.1007/s100169910075. PMID 10943794.

[7]. Marsh P, Holdstock J, Harrison C, Smith C, Price BA, Whiteley MS (June 2009). "Pelvic vein reflux in female patients with varicose veins: comparison of incidence between a specialist private vein clinic and the vascular department of a National Health Service District General Hospital". Phlebology. 24: 10813. doi:10.1258/phleb.2008.008041. PMID 19470861.

[8]. Whiteley MS (September 2014). "Part One: For the Motion. Venous Perforator Surgery is Proven and Does Reduce Recurrences". European Journal of Vascular and Endovascular Surgery. 48 (3): 23942. doi:10.1016/j.ejvs.2014.06.044. PMID 25132056.

[9]. Rutherford EE, Kianifard B, Cook SJ, Holdstock JM, Whiteley MS (May 2001). "Incompetent perforating veins are associated with recurrent varicose veins". European Journal of Vascular and 
10]. Shenoy KR. Varicose veins and deep vein thrombosis. Manipal manual of surgery 2009, Millennium edition: 87-89.

[11]. Phipps, Sands, Marek. Medical surgical nursing 6th ed. Philadelphia: Mosby Publication; 1999

[12]. Health J. varicose veins and spider veins. [online] Available from:http;//body and fitness.com/information/womenhealth/varicose.htm.

[13]. Campbell B (2006). "Varicose veins and their management" (https://www.ncbi.nlm.nih.gov/pmc/articles/PMC152694 5). BMJ. 333 (7562): 287-92. doi:10.1136/bmj.333.7562.287 (https://doi.org/10.1136\%2Fbmj.333.7562.287). PMC 1526945 (https://www.ncbi.nlm.nih.gov/pmc/articles/PMC1526945). PMID 16888305 (https://www.ncbi.nlm.nih. gov/pubmed/16888305).

[14]. Curri SB et al. (1989) "Changes of cutaneous microcirculation from elasto-compression in chronic venous insufficiency". In Davy A and Stemmer R (eds.) Phlebology '89, Montrouge, France, 'John Libbey Eurotext.

\section{AUTHORS PROFILE}

Dr. Arsheed Iqbal* Research officer Unani, (Scientist-III) Regional Research Institute of Unani Medicine, (Central Council for Research in Unani Medicine, Ministry of AYUSH, Govt. of India) University of Kashmir, Srinagar Jammu and Kashmir, India. $\mathrm{He}$ is currently working as M.D. Scholar Unani Medicine, since 2017. He has published more than 50 research papers in reputed international journals including Thomson Reuters (SCI \& Web of Science) and conferences including National and International and it's also available online. His main research work focuses on IlajBil-Tadbeer (Regimenal Therapy), Sonologist, Hirudotherapy expert. He has more than 15 years of research experience. 